\title{
The QA Pressure Measurement System: an accuracy and reliability study
}

D van Dijk ${ }^{1}$, G Aufdemkampe*,2 and S van Langeveld ${ }^{3}$

${ }^{1}$ Center Hospital Apeldoorn, PO Box 9014, 7300 DS Apeldoorn, The Netherlands; ${ }^{2}$ Polytechnic of Utrecht, Department of Physical Therapy, 3584 CJ Utrecht, The Netherlands, ${ }^{3}$ Rehabilitation Centre 'De Hoogstraat', Rembrandtkade 10, 3583 TM Utrecht, The Netherlands

\begin{abstract}
Objective: The main purpose of this study was to determine the accuracy and reliability of the Queen Alexandra Pressure Measurement System (QA PMS). Furthermore, we examined whether there were significant differences in measured pressures of the buttock area during sitting between normal subjects and spinal cord injured (SCI) patients.

Design: Accuracy (calibration) and reliability (test-retest) study.

Setting: The spinal cord unit of Tertiary Care Centre 'De Hoogstraat' in Utrecht, The Netherlands.

Patients: A convenience sample of 16 SCI patients and 15 normal subjects.

Main Outcome Measures: The accuracy was determined by using the Standard Error of the Mean (SEM, in $\mathrm{mmHg}$ ). The Technical Error of Measurement (TEM, in $\mathrm{mmHg}$ ) was calculated as measure for differences between two paired measurements. The reliability was determined by using an Intraclass Correlation Coefficient (ICC). Significant differences in measured pressures between both groups $(P<0.05)$ were determined by using an unpaired (two sample) $t$-test.

Results: Accuracy (calibration): mean SEM $=0.30( \pm 0.1) \mathrm{mmHg}$, indicating a high level of accuracy. Differences between two paired measurements: mean TEM calibration $=1.87$ $( \pm 0.76) \mathrm{mmHg}$; mean TEM normal subjects $=4.76( \pm 1.78) \mathrm{mmHg}$; mean TEM SCI patients $=6.34( \pm 2.19) \mathrm{mmHg}$. Reliability: mean $\mathrm{ICC}_{(3,1)}$ calibration $=0.85(95 \% \mathrm{CI}=0.74-$ $0.95)$; mean $\mathrm{ICC}_{(2,1)}$ normal subjects $=0.92 \quad(95 \% \quad \mathrm{CI}=0.90-0.94)$; mean $\mathrm{ICC}_{(2,1)} \quad \mathrm{SCI}$ patients $=0.90(95 \% \mathrm{CI}=0.88-0.92)$. The normal subjects had significantly higher mean pressures $(P=0.028)$ than the SCI patients (mean pressures 31.0 vs $28.5 \mathrm{mmHg}$ ), whilst the SCI patients had significantly higher peak-pressures $(P=0.0000)$ than the normal subjects (mean peak-pressures: 134.1 vs $75.7 \mathrm{mmHg}$ ).

Conclusions: The QA Pressure Measurement System has sufficient accuracy and good reliability as a measurement procedure. There are significant differences between the measured pressures of both groups: the significantly higher peak pressures of the SCI patients seem to be the most important.
\end{abstract}

Keywords: decubitus ulcer; reliability; accuracy; measurement; spinal cord injury

\section{Introduction}

Decubitus ulcers are one of the most important complications suffered by spinal cord injured (SCI) patients. Different terms are used for this phenomenon. According to Yarkony, ${ }^{1}$ the commonly used term 'pressure' ulcer is more appropriate as it denotes the principal etiological factor that causes ulceration. ${ }^{2-6}$ Shear-force is the second etiologic factor. ${ }^{2,3}$ Other

*Correspondence: G Aufdemkampe, Polytechnic of Utrecht, Department of Physical Therapy, Bolognalaan 101, 3584 CJ Utrecht, The Netherlands secondary etiologic factors in the formation of decutibus ulcers are; tissue properties including temperature, moisture, tissue viability, age and hygiene, ${ }^{4,5}$ nutritional status, ${ }^{7,8}$ general health/clinical status, activity level, posture and deformities ${ }^{7}$ and psychological factors. ${ }^{7} 9$ Additional contributing factors in the pathogenesis of decutibus ulcers are; decreased or absent sensibility, ${ }^{4,10,11}$ spastic or flaccid paralysis, ${ }^{4,10}$ coma and/or the (over)use of sedative drugs and edema. ${ }^{10}$ Ferguson-Pell ${ }^{4}$ suggests that tissue quality (ie, stiffness or tone), will influence the amount of deformation in the fat and muscle tissue and thus 
determines potential tissue damage. In short, the etiology of decutibus ulcers is considered to be multifactorial with perpendicular pressure and shearforces being the major causative factors.

The relationship between pressure intensity and pressure duration appears to be of special importance in the formation of decubitus ulcers. This relationship was examined by Groth (1942), cited by Daniel et al, ${ }^{12}$ Kosiak, ${ }^{8}$ Reswick and Rogers (1976), cited by Henderson et $a l^{13}$ Daniel et $a l^{12}$ and others. They found the pressure-time relationship to be a parabolic curve, indicating that high pressures for short duration are less damaging than low pressures for longer duration. Although the various authors found the curve's form to be parabolic, the relationship between pressure duration and pressure intensity was variable (see Figure 1).

There is no consensus in the literature concerning the critical threshold for this pressure-time relationship. According to Henderson et al ${ }^{13}$ the threshold in humans has been established at $60 \mathrm{mmHg}$ for $1 \mathrm{~h}$, cited by Henderson et $a l^{13}$ based on the studies of Kosiak, ${ }^{8}$ Reswick and Rogers and others.

Since perpendicular pressure and shear forces are considered to be the major factor in the aetiology of decutibus ulcers, it is important to design good pressure measurement tools for use in decubitus prevention and therapy. These tools need to be tested for accuracy, reliability and validity.

There have been many studies using different pressure measurement devices, measurement procedures and methods. ${ }^{3-6,11,13-27}$ These studies rarely record the reliability of the measurement procedure used, however the accuracy of the sensor used is usually mentioned. ${ }^{3,5,6,11,14-18,28}$

We found only one study which reported an intraobserver reliability regarding pressure measurement. Shields and Cook ${ }^{24,25}$ used an 'Ischiobarograph' and recorded the intra-observer reliability in terms of an

\section{Pressure-time relationship}

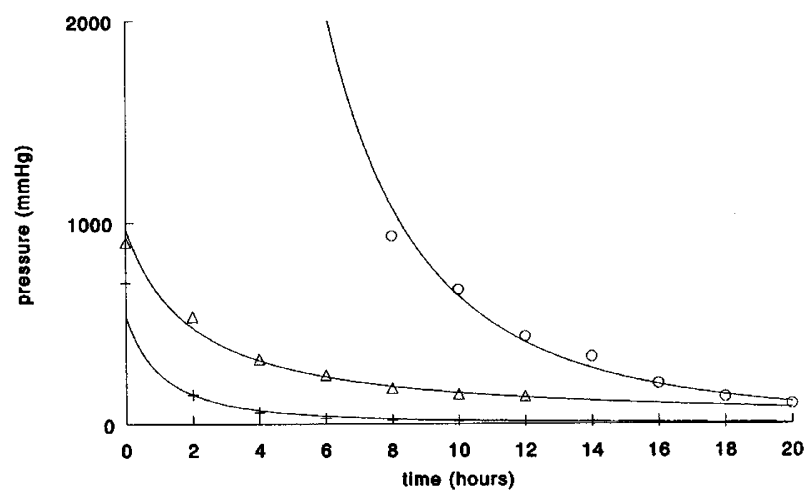

Figure 1 Adapted pressure-time relationships as determined by Reswick and Rogers $1976(+)$ (cited by Bar), ${ }^{26} \operatorname{Kosiak}^{8}\left({ }^{a}\right)$ and Daniel et $a l^{12}( \pm)$
Intraclass Correlation Coefficient (ICC). They found a mean $\mathrm{ICC}_{(1, \mathrm{~K})}$ of 0.95 in 20 normal subjects ${ }^{24}$ and a mean $\operatorname{ICC}_{(1,1)}$ of 0.92 in 18 SCI patients. ${ }^{25}$

The pressure sensor tested in our study, the Queen Alexandra Pressure Measurement System (QA PMS), has not been previously tested in the studied literature.

\section{Methods}

\section{Research objective}

The objective of this study was to determine the accuracy of the QA PMS and the reliability of the measurement procedure with the QA PMS. We were also interested to know whether a significant $(P<0.05)$ difference existed between the measured pressures recorded by normal subjects and subjects with spinal cord injuries.

\section{Research methods}

The QA Pressure Measurement System (see Figure 2) is a pressure sensing device which incorporates a pad encapsulating 256 inflatable pressure cells. These cells are spaced at intervals of $2.54 \mathrm{~cm}$ (1 inch) and record a pressure range of $0-300 \mathrm{mmHg}$.

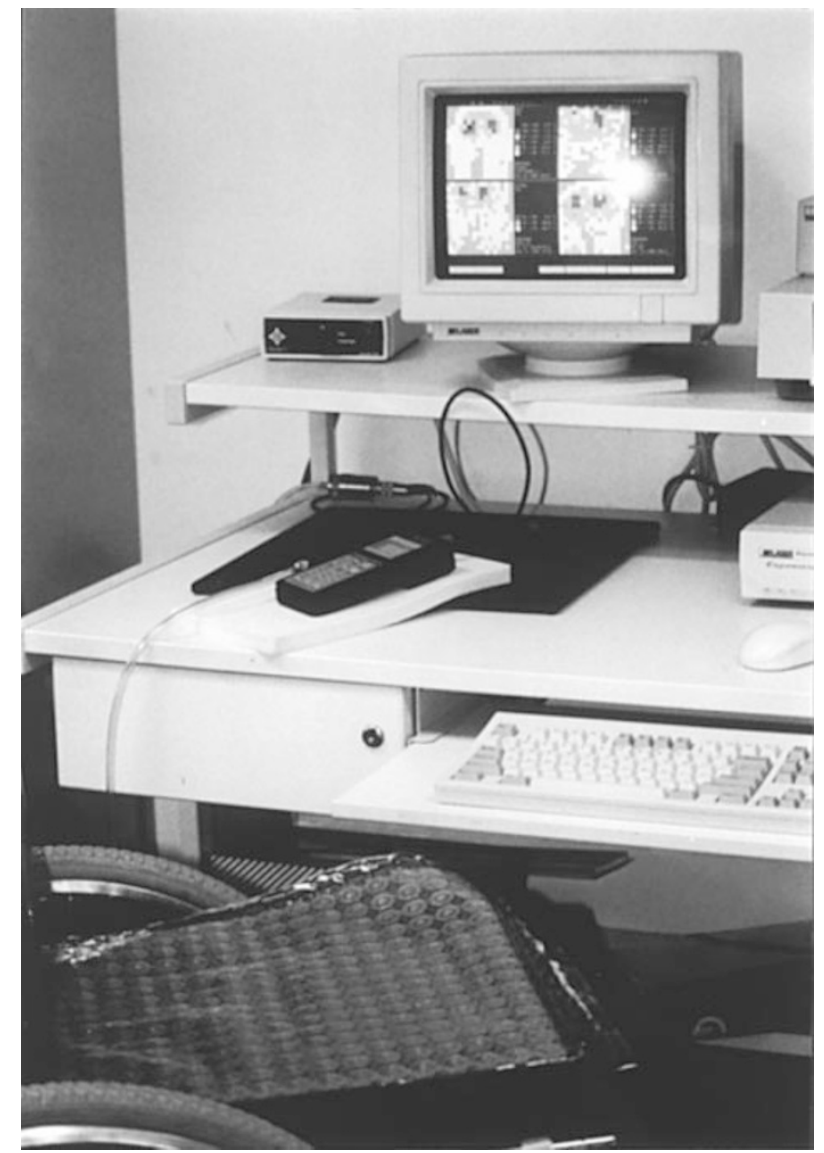

Figure 2 The Queen Alexandra Pressure Measurement System, and the wheelchair used in this study 
The pad is connected by a system interface to a computer which records two- and three-dimensional images of the pressure readings. The pressure can be read with an analogue manometer ${ }^{29}$ during the test. However, we found that the analogue manometer could have a negative influence on the test results since reading the small supplied manometer could be more difficult than reading a digital manometer. We therefore replaced the analogue manometer with a digital one (Delta Ohm, type HD 8804, inaccuracy $\pm 0.05 \%$, with a pressure probe type TP $805 / \mathrm{DP}$, inaccuracy $\pm 0.7 \%)^{30}$ (see Figure 3 ). The accuracy and reliability of the QA PMS is not mentioned in the User Reference Manual. ${ }^{29}$ Furthermore, the reference manual does not discriminate between perpendicular and shear forces.

The QA PMS has several different measurement methods, ${ }^{29}$ we chose the 'inflation method with actual pressure', with a pressure increment of $5 \mathrm{mmHg}$.

The study was conducted with two convenience samples (see Table 1). Sample 1 consisted of 15 normal subjects and sample 2 consisted of 16 SCI patients staying in the rehabilitation centre. The level of the

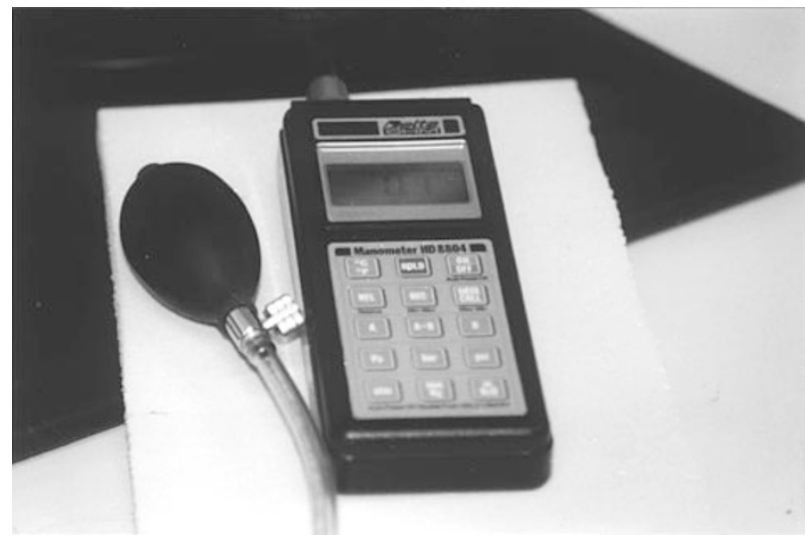

Figure 3 The digital manometer (Delta OHM) used in this study lesions from the SCI patients varied from $\mathrm{C}_{4}$ (incomplete) to $\mathrm{L}_{1}$ (incomplete). Ten persons were tetraplegic and six persons were paraplegic, whereby ten lesions were complete and six lesions were incomplete. For specification of the severity of the paralysis of the incomplete SCI patients see Table 2.

The following inclusion/exclusion criteria were used. The normal subjects were not to experience any kind of complaint during testing (eg, back-pain), and capable of sitting completely still during the tests. The SCI patients were required to have a SCI of at least 3 months duration, independent of the level or nature of the lesion, an abnormal sensibility in the buttock-area (ie, anaesthesia, paraesthesia or hypaesthesia), capable of sitting $3 \times 3 \mathrm{~h}$ a day, sitting completely still during the tests, not have any decubitus ulcers in the buttock-area during testing and a sitting area greater than $45 \times 45 \mathrm{~cm}$.

All subjects read and signed an informed consent. The study-protocol had been approved by the scientific and ethics commission of the Tertiary Care Centre De Hoogstraat.

The accuracy of the QA pad was checked by calibration using eight standardized weights $(2,5,10$, $15,20,22,25$ and $29 \mathrm{~kg}$ ), which were placed on the pad and measured twice by the first author. Thereby, we also determined the intra-observer reliability.

Table 2 Specification of the severity of the paralysises of the incomplete SCI patients

\begin{tabular}{lcccc}
\hline ID- & \multicolumn{2}{c}{ Motor level } & \multicolumn{2}{c}{ Sensibility level } \\
number & Left & Right & Left & Right \\
\hline BD2 & L1 & L1 & L1 & L2 \\
BD3 & Complete C7 Complete C7 & C5 & C5 \\
BD5 & Complete C6 Complete C5 & C5 & C5 \\
BD8 & C4 & C4 & T6 & T6 \\
BD9 & T12 & T12 & T12 & T12 \\
BD16 & C4 & C4 & C4 & C4 \\
\hline
\end{tabular}

L, lumbar; C, Cervical; T, Thoracic

Table 1 Description of the two samples

\begin{tabular}{lcc}
\hline & $\begin{array}{c}\text { Normal } \\
\text { subjects }(\mathrm{n}=15)\end{array}$ & $\begin{array}{c}\text { SCI patients } \\
(\mathrm{n}=16)\end{array}$ \\
\hline Sex & $7 \mathrm{M}, 8 \mathrm{~F}$ & $10 \mathrm{M}, 6 \mathrm{~F}$ \\
Mean age $\pm \mathrm{SD}$ (years) & $22.5 \pm 2.0$ & $35.5 \pm 16.1$ \\
Mean weight \pm SD $(\mathrm{kg})$ & $74 \pm 10.2$ & $70.6 \pm 16.9$ \\
Mean length $\pm \mathrm{SD}(\mathrm{cm})$ & $178.8 \pm 9.2$ & $176.3 \pm 7.8$ \\
Mean SCI duration $\pm \mathrm{SD}$ & & $20.4 \pm 35.0$ \\
$\quad($ range in months) & $3-144)$ \\
Level of SCI & & 10 cervical, 5 thoracic, 1 lumbar \\
Nature of SCI & 10 complete, 6 incomplete \\
Any form of visible spasticity & 3 persons \\
History of decubitus ulcers & 11 persons \\
\hline
\end{tabular}

SD, Standard Deviations 
The reliability of the measurement procedure with the QA PMS and the differences in measured pressures between both groups were determined as follows; all subjects were tested four times by two observers (two measurements by each observer) under standardized conditions, which took twice 45 min per subject (two sessions). The order of testing by the observers was determined at random for the first session. The second session took place in the same order as the first. The measurements were taken in a standardized Orthopedia Ideaal Fix. wheelchair (no armrests; standard Ushaped foam cushion [ $4 \mathrm{~cm}$ massive latex and $4 \mathrm{~cm}$ perfolatex] of $45 \times 45 \mathrm{~cm}$, the front of the cushion was $2 \mathrm{~cm}$ higher than the back; standard soft high backed [38 cm high, seat-to-backrest angle $85^{\circ}$ ]; seat height $59 \mathrm{~cm}$ from the floor, making an angle with the in height adjustable footsteps [with calves support] of $105^{\circ}$ ).

The subjects were seated in the wheelchair, with the back rested against the backrest, buttocks positioned in the back of the seat and the feet at the adjustable footsteps, with the thighs making contact to the cushion and the calves supported by the calves support. The hands rested on the thighs. The subjects remained in this test position for $10 \mathrm{~min}$ prior to the pressure measurement being recorded, to give the foam cushion and the body time to adapt to each other's geometry. According to Garber et $a l^{16}$ this process can take $30 \mathrm{~min}$ (depending on ambient conditions). However, Garber et al used $15 \mathrm{~min}$.

Ferguson-Pell ${ }^{4}$ stated that one should wait 510 min after placement of the measurement device to ensure that the material and the body have conformed to each other. The measurement was then taken. Finally, the subjects left the wheelchair and the whole procedure was repeated by the next observer. Then both observers took their second measurement in the same order as their first.

\section{Statistical analysis}

The Standard Error of the Mean (SEM) was calculated to determine the accuracy of the measurement pad and the Technical Error of Measurement (TEM) was calculated to determine the differences between two paired measurements of the first author. ${ }^{31} \mathrm{We}$ performed $\operatorname{ICC}_{(3,1)}$ calculations as measure of intrarater reliability for the calibration measurements and $\mathrm{ICC}_{(2,1)}$ calculations as measure of inter-rater reliability for both studied groups. Portney and Watkins ${ }^{32}$ defined an $\mathrm{ICC}_{(2,1)}>0.75$ to be good and an $\mathrm{ICC}_{(2,1)}<0.75$ to be poor/moderate. Unpaired (two sample) $t$-test with an alfa of 0.05 was used to determine any significant differences in measured pressures between both samples of all first measurements of the first author.

For statistical analysis we used the computer programs Number Cruncher Statistical System (NCSS) version $5.0^{33}$ and ICC version $1.03 .^{34}$

\section{Results}

Accuracy (see Table 3)

The Standard Error of the Mean (SEM) of the calibration measurements $(n=8)$ was calculated as the measure for accuracy. The mean SEM was $0.3( \pm 0.1)$ $\mathrm{mmHg}$, indicating a high level of accuracy. The mean Technical Error of Measurement (TEM) of the calibration measurements was $1.87( \pm 0.76) \mathrm{mmHg}$.

We also calculated the TEM of the measurements of the first observer of both samples. The mean TEM for the normal subjects ( $n=15,30$ observations) was 4.76 $( \pm 1.78) \mathrm{mmHg}$ and the mean TEM for the SCI patients $(n=16,32$ observations) was $6.34( \pm 2.19)$ $\mathrm{mmHg}$.

\section{Reliability (see Table 3)}

Calibration The raw data of the calibration measurements ranged from $0-30 \mathrm{mmHg}$. These data were tested for (intra-observer) reliability with an $\mathrm{ICC}_{(3,1)}$. With the exception of the $2 \mathrm{~kg}$ weight $\left(\mathrm{ICC}_{(3,1)}=0.56\right.$ $[95 \% \quad \mathrm{CI}=0.47-0.64])$, all reliabilities were good $\left(\mathrm{ICC}_{(3,1)}>0.75\right)$, mean $\quad \mathrm{ICC}_{(3,1)}=0.85 \quad(95 \%$ $\mathrm{CI}=0.74-0.95)$, range: $0.56-0.93(95 \% \mathrm{CI}=0.47-$ $0.95)$. The mean of all mean-pressures was $7.5( \pm 4.9)$ $\mathrm{mmHg}$ and the mean of all maximum (peak-) pressures was $20.6( \pm 7.9) \mathrm{mmHg}$ (see Table 3 ).

Normal subjects The raw data of the normal subjects ( $n=15,60$ observations) ranged from $0-95 \mathrm{mmHg}$. These data were tested for inter-observer reliability with an $\mathrm{ICC}_{(2,1)}$. All reliabilities were good $\left(\operatorname{ICC}_{(2,1)}>0.75\right)$. Mean $\quad \operatorname{ICC}_{(2,1)}=0.92 \quad(95 \%$ $\mathrm{CI}=0.90-0.94)$, range: $0.82-0.97(95 \% \mathrm{CI}=0.78-$ $0.97)$ mean of the separate mean-pressures of all first measurements of the first author was $31.0( \pm 3.7)$ $\mathrm{mmHg}$ and the mean of the separate maximum (peak-) pressures was $75.7( \pm 9.6) \mathrm{mmHg}$ (see Table 3 ). The peak-pressures were mostly located where both ischical tuberosities were expected to be.

SCI patients The raw data of the SCI patients $(n=16$, 64 observations) ranged from $0-185 \mathrm{mmHg}$. Again, we used an $\operatorname{ICC}_{(2,1)}$ to determine the inter-observer

Table 3 Results

\begin{tabular}{lcccc}
\hline $\begin{array}{l}\text { Mean } \\
\begin{array}{l}S E M \pm S D \\
(\mathrm{mmHg})\end{array}\end{array}$ & $\begin{array}{c}\text { Mean TEM } \\
\pm S D \\
(\mathrm{mmHg})\end{array}$ & Mean ICC & $\begin{array}{c}\text { Mean } \\
\text { Pmean } \pm S D\end{array}$ & $\begin{array}{c}\text { Mean Pmax } \\
\pm S D \\
(\mathrm{mmHg})\end{array}$ \\
\hline $0.3 \pm 0.1$ & $1.87 \pm 0.76$ & $0.85^{*}$ & $7.5 \pm 4.9$ & $20.6 \pm 7.9$ \\
& $4.76 \pm 1.78$ & $0.92^{\dagger}$ & $31.0 \pm 3.7$ & $75.7 \pm 9.6$ \\
& $6.34 \pm 2.19$ & $0.90^{\#}$ & $28.5 \pm 6.3$ & $134.1 \pm 33.9$ \\
\hline
\end{tabular}

Pmean, mean of all pressures of all first measurements of the first observer; Pmax, mean of all maximum (peak-)pressures of all first measurements of the first observer. ${ }^{*} \mathrm{ICC}_{(3,1)} 95 \%$ $\mathrm{CI}=0.74-0.95 ;{ }^{\dagger} \mathrm{ICC}_{(2,1)} 95 \% \mathrm{CI}=0.90-0.94 ;{ }^{\#} \mathrm{ICC}_{(2,1)} 95 \%$ $\mathrm{CI}=0.88-0.92$ 
reliability of the measurement procedure with the QA PMS. All reliabilities were good $\left(\mathrm{ICC}_{(2,1)}>0.75\right)$. Mean $\mathrm{ICC}_{(2,1)}=0.90(95 \% \mathrm{CI}=0.88-0.92)$, range: $0.79-0.96$ $(95 \% \mathrm{CI}=0.73-0.97)$.

The mean of the separate mean-pressures, determined by all first measurements of the first author, was $28.5( \pm 6.3) \mathrm{mmHg}$ and the mean of the separate maximum pressures was $134.1( \pm 33.9) \mathrm{mmHg}$ (see Table 3).

The most striking differences between both studied groups were in the mean mean-pressure and the difference in mean maximum pressure. The differences in the separate mean pressures and the differences in the separated measured maximum pressures were tested by an unpaired (two-sample) $t$-test. Both differences appeared to be significant $(P<0.05)$. The normal subjects appeared to deliver a significantly higher mean pressure to the system than the SCI patients $(P=0.028)$. However, the SCI patients appeared to have significantly higher peak-pressures than the normal subjects $(P=0.0000)$.

\section{Discussion}

The most important difference between the two groups was the difference in maximal measured (peak-) pressures (different pressure ranges: $0-95$ vs $0-$ $185 \mathrm{mmHg}$ ). A possible explanation for this finding could be the motor-, sensibility-, vegetative- and vasomotor disturbances arising from a SCI, causing changes in muscle and tissue tone and volume in the buttock area. The authors hypothesized that the muscle and tissue wasting in the buttock area in the studied SCI group (duration of $\mathrm{SCI} \geqslant 3$ months), could be the most important cause of the significantly higher peakpressures in this group $(P=0.0000)$. Both ischial tuberosities can pronounce strongly as a result of the wasting, thus causing high peak-pressures.

The differences in separate mean pressures was much smaller but also significant $(P=0.028)$. The authors hypothesized that the reason for the higher mean pressures in the normal group, compared to the SCI group, could also be the muscle and tissue wasting in the SCI group.

The buttock contact area increases and becomes flatter as a result of tissue transformation, thereby reducing the mean pressure since the same weight is distributed over more QA PMS cells.

The reliability coefficients found in this study are comparative with those found by Shields and $\operatorname{Cook}^{24,25}$ who used an 'Ischiobarograph' to study the effects of different seat angles and lumbar support thickness on the buttock pressures of both normal subjects and SCI patients. They also used an ICC to determine the reliability and found mean intraobserver reliabilities (mean $\mathrm{ICC}_{(1, \mathrm{k})}$ ) of 0.95 for normal subjects ${ }^{24}(n=20)$ and 0.92 for SCI patients ${ }^{25}$ $(n=18)$.

Hobson $^{3}$ used an Oxford Pressure Monitor to study the effects of different sitting positions on the pressures at the body-seat interface of normal subjects and SCI patients. In accordance with the results of our study, Hobson found that, whilst the measured average pressures varied little between both groups, the SCI patients had significantly higher maximum pressures than non-disabled subjects. However, Hobson does not mention the level of significance and it is not known by the authors whether the Oxford Pressure Monitor has been studied on reliability or not. Hobson attributes these differences in measured pressures between both groups to spinal/ pelvic deformities and atrophy over the ischial tuberosities.

The results of our study suggest that, if the pressure-time relationship is the most important factor in the pathogenesis of decubitus, SCI patients run very high risks of developing decubitus ulcers in the buttock area. This requires a more objective and good anti-decubitus policy.

The QA Pressure Measurement System is a sufficiently accurate measurement tool with weights heavier than $5 \mathrm{~g}$ (acceptable mean SEM of 0.30 $[ \pm 0.11] \mathrm{mmHg})$. The measurement procedure with the QA PMS has good reliability $\left(\operatorname{ICC}_{(2,1)}>0.75\right)$ in both groups. Mean $\mathrm{ICC}_{(2,1)}$ normal subjects $=0.92$ $(95 \% \mathrm{CI}=0.90-0.94) ;$ mean $\mathrm{ICC}_{(2,1)}$ SCI patients $=0.90(95 \% \mathrm{CI}=0.88-0.92)$.

There were differences between both groups regarding range of measured pressures and regarding average pressures and maximum (peak-) pressures.

The difference between the average pressures was small but never the less significant $(P=0.028)(31.0$ $\pm 3.7 \mathrm{mmHg}$ for the normal subjects and 28.5 $\pm 6.3 \mathrm{mmHg}$ for the SCI patients). The difference in the maximum (peak-) pressures was larger and also significant $(P=0.0000)$, and was higher for the SCI patients than the normal subjects $(143.1 \pm 33.9 \mathrm{mmHg}$ and $75.7 \pm 9.6 \mathrm{mmHg}$ respectively).

\section{Acknowledgements}

Acknowledgements are due to $\mathrm{R}$ Peerenboom for her comments on earlier versions of this article, to $\mathrm{R}$ van Elsland, technician of 'De Hoogstraat', Utrecht, The Netherlands, as second observer and to $\mathrm{L}$ te Boekhorst Physical Therapist of 'De Hoogstraat' for clarifying the discussion.

\section{References}

1 Yarkony GM. Pressure ulcers: a review. Arch Phys Med Rehabil 1994; 75: $908-917$.

2 Dinsdale SM. Decubitus ulcers: role of pressure and friction in causation. Arch Phys Med Rehabil 1974; 55: 147-152.

3 Hobson DA. Comparative effects of posture and pressure and shear at the body-seat interface. J Rehabil Res Dev 1992; 29: 21 31 .

4 Ferguson-Pell MW. Seat cushion selection. J Rehabil Res Dev 1990; 27 Clin suppl 2: 49-73.

5 Kwiatkowski RJ, Inigo RM. A closed loop automated seating system. J Rehabil Res Dev 1993; 30: 393 - 404 . 
6 Sprigle SH, Chung KC, Brubaker CE. Reduction of sitting pressures with custom contoured cushions. J Rehabil Res Dev 1990; 27: $135-140$

7 Hobson DA, Tooms RE. Seated lumbar/pelvic alignment: a comparison between spinal cord-injured and noninjured groups. Spine 1992; 17: 293-298.

8 Kosiak M. Etiology and pathology of ischemic ulcers. Arch Phys Med Rehabil 1959; 40: $62-69$.

9 Rothery FA. Preliminary evaluation of a pressure clinic in a new spinal injuries unit. Paraplegia 1989; 27: $36-40$.

10 Houle RJ. Evaluation of seat devices designed to prevent ischemic ulcers in paraplegic patients. Arch Phys Med Rehabil 1969; 50: $587-594$.

11 Souther SG, Carr SD, Vistnes LM. Wheelchair cushions to reduce pressure under bony prominences. Arch Phys Med Rehabil 1974; 55: $460-464$.

12 Daniel RK, Priest DL, Wheatley DC. Etiologic factors in pressure sores: An experimental model. Arch Phys Med Rehabil 1981; 62: $492-498$.

13 Henderson JL, Price SH, Brandstater ME, Mandac BR. Efficacy of three measures to relieve pressure in seated persons with spinal cord injury. Arch Phys Med Rehabil 1994; 75: 535-539.

14 Sprigle SH, Faisant TE, Chung KC. Clinical evaluation of custom-contoured cushions for the spinal cord injured. Arch Phys Med Rehabil 1990; 71: 655-658.

15 Bush CA. Study of pressures on skin under ischial tuberosities and thighs during sitting. Arch Phys Med Rehabil 1969; 50: $207-$ 213.

16 Garber SL, Krouskop TA, Carter RE. A system for clinically evaluating wheelchair pressure-relief cushions. Am J Occup Ther (AJOT) 1978; 32: $565-570$.

17 Krouskop TA, Williams R, Noble P, Brown J. Inflation pressure effect on performance of air-filled wheelchair cushions. Arch Phys Med Rehabil 1986; 67: $126-128$.

18 Gilsdord P, Patterson R, Fisher S, Appel N. Sitting forces and wheelchair mechanics. J Rehabil Res Dev 1990; 27: 239-246.

19 Gilsdord P, Patterson R, Fisher S. Thirty-minute continuous sitting force measurements with different support surfaces in the spinal cord injured and able-bodies. J Rehabil Res Dev 1991; 28: $33-38$.
20 Kosiak M. A mechanical resting surface: Its effect on pressure distribution. Arch Phys Med Rehabil 1976; 57: 481 - 484.

21 Bennet $\mathrm{L}$ et al. Skin stress and bloodflow in sitting paraplegic patients. Arch Phys Med Rehabil 1984; 65: 186-190.

22 Seymour RJ, Lacefield WE. Wheelchair cushion effect on pressure and skin temperature. Arch Phys Med Rehabil 1985; 66: $103-108$

23 Patterson RP, Fisher SV. Sitting pressure-time patterns in patients with quadriplegia. Arch Phys Med Rehabil 1986; 67: $812-814$

24 Shields RK, Cook TM. Effect on seat angle and lumbar support on seated buttock pressure. Phys Ther 1988; 68: 1682-1686.

25 Shields RK, Cook TM. Lumbar support thickness: Effect on seated buttock pressure in individuals with and without spinal cord injury. Phys ther 1992; 72: 218-226.

26 Bar CA. Evaluation of cushions using dynamic pressure measurement. Prostet Orthot Int 1991; 15: $232-240$.

27 Spijkerman DCM, Terburg M, Goossens RHM, Stijnen T. Effects of inflation pressure and posture on the body-seat interface pressure of spinal cord injured patients seated on an air-filled wheelchair cushion. J Rehabil Sci 1995; 8: 8-12.

28 Patterson RP, Fisher SV. The accuracy of electrical transducers for the measurement of pressure applied to the skin. IEEE Transactions on Biomedical Engineering (BME) 1979; 26: 450456.

29 User Reference Manual: pressure measurement program. QA Pressure measurement system Gabel Medical Instruments Ltd. 1994; 3rd edn. Canada.

30 Instructions Manual. HD 8804 Multifunctional digital microprocessor pressure and temperature gauge. Delta OHM, Italy.

31 Knapp TR. Technical Error of Measurement: A Methodological Critique. Am J Phys Anthr 1992; 87: 235-236.

32 Portney LG, Watkins MP. Foundations of Clinical Research, applications to practise. Norwalk, Appleton \& Lange 1993; 509 516.

33 Hintze JL. Number Cruncher Statistical System (NCSS) Version 5.0 - Student. $1 / 88$ 1988, Kaysville, Utah.

34 Chambers R. ICC Version 1.03. 1992; Sidney, Australia. 